\title{
Analysis of Thermal Protection System in Flex Seal of a Rocket Motor
}

\author{
Charitha Krishna P, Balakrishna Murthy V, Chandra Mohan R
}

\begin{abstract}
A Thermal protection system is used to protect the rocket from the heat generated by the hot gases. A thermal boot is used as the thermal protection system at the outside of the nozzle to protect the flex seal. The objective of the present work is to design the thermal protection system for flex seal using different composite materials for single time of flight and to study the ablation of the materials. The problem is modelled using commercial ANSYS software. 3-D Axi-symmetric transient thermal analysis is performed for the flex seal along with thermal protection system made of composite materials. The initial and boundary conditions are applied to meet the industrial requirement. From this analysis, thermal protection system made of different composite materials is studied and one is suggested based on ablation and weight reduction.
\end{abstract}

Index Terms: FEM, Flex Seal, Thermal protection system, Axi-Symmetry

\section{INTRODUCTION}

Major of the inventions use seals. Seal is the mechanical component which is used where ever there is a transfer of liquid and gases. Thermal protection system for flex seal is of two types. 1) Classical protection, where special type of rubber is used to protect the flex seal. 2) Self protected system, where the extended shims are used. The present analysis studies the self protected system which is used in rocket to maintain the flexibility, connection and controlling the thrust vector of the rocket.

\section{LITERATURE SURVEY}

Borie V.[1] An aero thermal chemical analysis on ablation of the carbon-carbon materials in the throat of the nozzle of a rocket motor is conducted. Clark [2] an analysis for predicting the time varying study of a one dimensional ablative thermal protection system for a high energy air environment is performed. Naveen.j [3] performed a thermal analysis of rocket nozzle to find the total ablation of nozzle. The effect of thermal conductivity, density, specific heat and layer orthotropic is studied. Ajay Babu [4] has done various parametric studies by varying number of shims, thickness of the elastomeric and materials. He suggested the thickness of rubber pad and count of shims with preferable materials. Eswar Kumar [5] presented the shim to rubber percentage to be within the volume, by varying percentage and number of shims when same shim to rubber percentage was taken and inter laminar effect between shims and elastomeric pads are also studied. Prakash.D [6] has done various parametric

Revised Manuscript Received on November 05, 2019.

Charitha Krishna P, Assistant Professor, Department of Mechanical Engineering, SVIET, Nandamuru, Andhra Pradesh, India

Balakrishna Murthy V, Professor, Department of Mechanical Engineering, VRSEC, Vijayawada, Andhra Pradesh, India.

Chandra Mohan R, Chairman, Resins \& Allied Products, Nidamanuru, Vijayawada, Andhra Pradesh, India.. studies by varying shim thickness in a flex seal, mismatch in materials of shim and elastomeric pad, application of composite materials for all components except rubber pads. D. Madhav [7] studied about the self protection of the flex seal using Finite Element Analysis. The study is conducted to evaluate the thickness of the extended shims and thermal boot for the duration of $51 \mathrm{sec}$. Dr. V. Bala Krishna Murthy and Dr. G. Sambasiva rao [8] studied micromechanics of unidirectional continuous fiber reinforced composite for the prediction of the mechanical and thermal properties of the lamina with perfect bonding and the partial circumferential de bonding at the fiber matrix interface. Panithapu Charitha krishna [9] performed a transient thermal analysis on self protecting flex seal system as well as classical protection system for $65 \mathrm{sec}$ time of flight and compared the both systems for optimum weight and suggested the material.

\section{CONCLUSION FROM LITERATURE SURVEY}

Many authors did experiments as well as analysis for thermal erosion of the liners inside the nozzles. Some of the literature is available on the erosion of thermal boot made of rubber and for self -protected seal made of carbon phenolic and silica phenolic. No literature is available where thermal analysis is done for epoxy composite material for self -protected seal and boot made of composite material.

So, the scope of the present work is to predict the analysis of thermal protection system of flex nozzle of rocket motor using Finite Element Method using different materials.

\section{PROBLEM MODELING}

A thermal protection system of flex seal of a rocket nozzle is analysed with composite material using Finite Element Analysis. One end of the flex seal is called fore end ring. It is a movable ring. The other is called aft end ring which is fixed. When actuator forces the nozzle to turn at a particular angle, the layers of the seal shears and finally total vector angle is achieved. It allows the deflection of greater than $\pm 5^{0}$. In this model aft end and fore end rings are made of steel, shims and thermal boot are made of composite material and elastomeric pads are made of rubber. The properties of the materials are shown in Tables 1-5 [7,8]

This flex seal is of two types, Cylindrical and conical. In cylindrical the flex seal will not make any angle with vertical axis from the pivot point. Where as in conical it makes an angle with the vertical axis. The angle depends on the significance of use. A conical flex system is shown in the Figure 1. The combustion gases with high temp and pressure forces into the 
cavity stagnate their and act as thermal load.

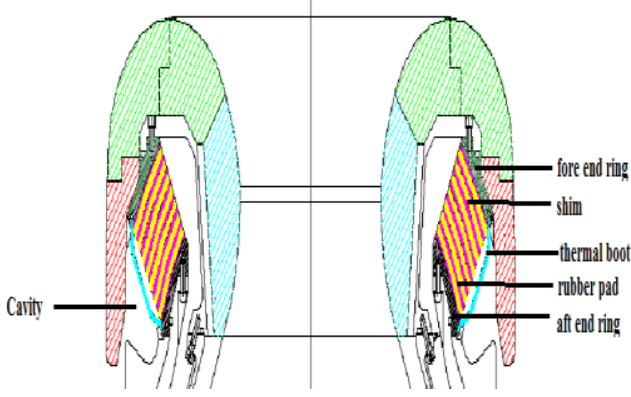

Figure 1: Conical flex seal [9]

The material of the shims i.e. composite material should have both thermal and structural properties for safe functioning of the rocket. Therefore, composite materials namely carbon phenolic, silica phenolic and carbon epoxy behaviour is studied for the selected design. The dimensions of the cavity are as shown in the Figure 2

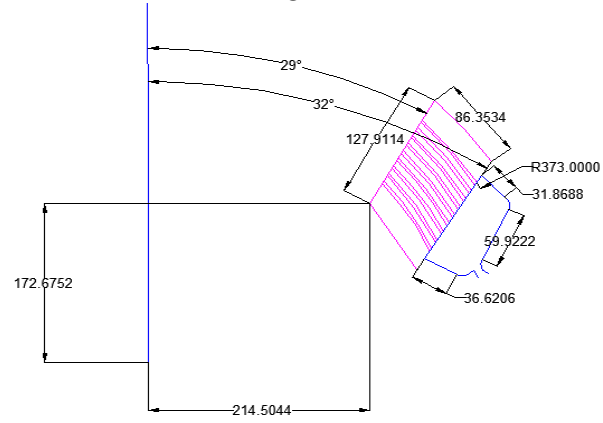

Figure 2: Dimensions of the flex seal

In the cavity the hot gases will stagnate and act as a thermal load. The thermal protection system should safe guard the flex seal not to be get damaged because of the heat flux generated in the cavity.

Therefore, the heat value is calculated from the equation $\mathrm{Q}=\mathrm{mc}_{\mathrm{p}} \Delta \mathrm{t}$. The mass is calculated by $\mathrm{m}=\rho \mathrm{v}$. The effective volume is calculated by subtracting the volume of protection system from the volume of the cavity. Specific heat of the gases is taken as $3026 \mathrm{~J} / \mathrm{Kg} \mathrm{K}$. The temperature of the gases will be in the range of $2400 \mathrm{~K}-3000 \mathrm{~K}$. So final temperature is taken as $3000 \mathrm{~K}$ and the initial temperature is $300 \mathrm{~K} . \Delta \mathrm{t}=2700 \mathrm{~K}$. [7] After calculating the Q, it is divided by the surface area to get $\mathrm{q}$ (heat flux).

The Thermal load which acts on the thermal protection system is a time changing value i.e transient. Therefore, a percentage of heat deration is assumed and a transient thermal analysis is done.

A thermal protection system is designed as shown in the Figure 3 and all the shims expect bottom two are extended for $15 \mathrm{~mm}$. The bottom one is extended $10 \mathrm{~mm}$ only because for $15 \mathrm{~mm}$ extension, there may be a chance of hitting during vectoring positions. An extended portion of $5 \mathrm{~mm}$ thickness is also added along with the shims extension to decrease the heat flux value.

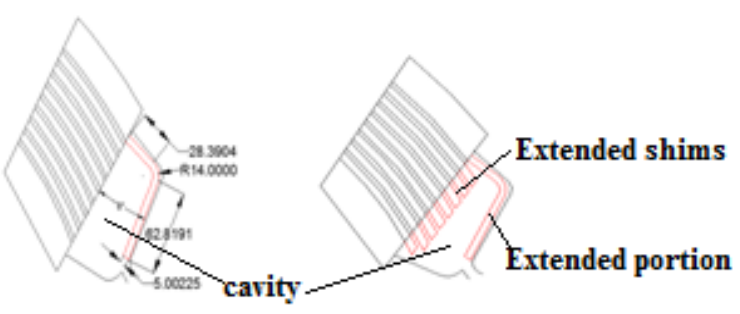

Figure 3: Design of thermal protection system

Table 1 Material Properties of Carbon phenolic [7]

\begin{tabular}{|l|c|c|c|c|c|c|}
\hline \multicolumn{7}{|c|}{ carbon phenolic } \\
\hline Temperature, $\mathrm{K}$ & 300 & 395 & 533 & 811 & 1366 & 1922 \\
\hline $\mathrm{kx}, \mathrm{W} / \mathrm{mm} \mathrm{K}$ & 0.00134 & 0.00141 & 0.00157 & 0.00202 & 0.00388 & 0.00709 \\
\hline $\mathrm{ky}, \mathrm{W} / \mathrm{mm} \mathrm{K}$ & 0.00134 & 0.00141 & 0.00157 & 0.00202 & 0.00388 & 0.00709 \\
\hline $\mathrm{kz}, \mathrm{W} / \mathrm{mm} \mathrm{K}$ & 0.0009 & 0.0009 & 0.0009 & 0.00105 & 0.00194 & 0.00492 \\
\hline Temperature, $\mathrm{K}$ & 300 & 395 & 533 & 811 & 1366 & 1922 \\
\hline specific heat, $\mathrm{J} / \mathrm{kg} \mathrm{K}$ & 921.1 & 1549.1 & 1758.5 & 1967.8 & 2051.5 & 2072.5 \\
\hline Temperature, K & 300 & 395 & 533 & 811 & 1366 & 1922 \\
\hline Density, $\mathrm{kg} / \mathrm{mm}^{\wedge} 3$ & $1.44 \mathrm{E}-06$ & $1.44 \mathrm{E}-06$ & $1.44 \mathrm{E}-06$ & $1.44 \mathrm{E}-06$ & $1.44 \mathrm{E}-06$ & $1.44 \mathrm{E}-06$ \\
\hline
\end{tabular}

Table 2. Material Properties of Silica phenolic [7]

\begin{tabular}{|l|c|c|c|c|}
\hline \multicolumn{5}{|c|}{ silica phenolic } \\
\hline Temperature, $\mathrm{K}$ & 300 & 533 & 811 & 1366 \\
\hline $\mathrm{kx}, \mathrm{W} / \mathrm{mmK}$ & 0.00079 & 0.00077 & 0.00074 & 0.00152 \\
\hline $\mathrm{ky}, \mathrm{W} / \mathrm{mmK}$ & 0.00079 & 0.00077 & 0.00074 & 0.00152 \\
\hline $\mathrm{kz}, \mathrm{W} / \mathrm{mm} \mathrm{K}$ & 0.00036 & 0.00035 & 0.00035 & 0.00099 \\
\hline Temperature, $\mathrm{K}$ & 300 & 533 & 811 & 1366 \\
\hline specificheat, $\mathrm{J} / \mathrm{kg} \mathrm{K}$ & 837.4 & 1161.5 & 1395.6 & 1674.7 \\
\hline Temperature, $\mathrm{K}$ & 300 & 533 & 811 & 1366 \\
\hline density, $\mathrm{kg} / \mathrm{mm}^{\wedge} 3$ & $1.65 \mathrm{E}-06$ & $1.65 \mathrm{E}-06$ & $1.65 \mathrm{E}-06$ & $1.65 \mathrm{E}-06$ \\
\hline
\end{tabular}

Table 3 Material Properties of Carbon Epoxy [8]

\begin{tabular}{|l|l|c|}
\hline \multicolumn{3}{|c|}{ Carbon epoxy (T 300 fiber, epoxy) } \\
\hline \multirow{3}{*}{ conductivity, W/mm K } & $\mathrm{kx}$ & 0.0502633 \\
\cline { 2 - 3 } & $\mathrm{ky}$ & 0.007152 \\
\cline { 2 - 3 } & $\mathrm{kz}$ & 0.007152 \\
\hline specific heat, J/kg K & \multicolumn{2}{|c|}{962.4639} \\
\hline density, $\mathrm{kg} / \mathrm{mm}^{\wedge} 3$ & \multicolumn{2}{|c|}{$1.56 \mathrm{E}-06$} \\
\hline
\end{tabular}

Table 4 Material Properties of Steel [7]

\begin{tabular}{|l|c|c|c|c|c|c|c|}
\hline \multicolumn{7}{|c|}{ Steel } \\
\hline Temperature, $\mathrm{K}$ & 300 & 400 & 600 & 800 & 1000 & 1200 & 1500 \\
\hline conductivity, $\mathrm{W} / \mathrm{mm} \mathrm{K}$ & 0.0146 & 0.0166 & 0.0198 & 0.0226 & 0.0254 & 0.028 & 0.0317 \\
\hline Temperature, $\mathrm{K}$ & 300 & 400 & 600 & 800 & 1000 & 1200 & 1500 \\
\hline Specific heat, $\mathrm{J} / \mathrm{kg} \mathrm{K}$ & 459 & 515 & 557 & 582 & 611 & 640 & 682 \\
\hline Temperature, $\mathrm{K}$ & 300 & 400 & 600 & 800 & 1000 & 1200 & 1500 \\
\hline density, $\mathrm{kg} / \mathrm{mm}^{\wedge} 3$ & $7.90 \mathrm{E}-06$ & $7.90 \mathrm{E}-06$ & $7.90 \mathrm{E}-06$ & $7.90 \mathrm{E}-06$ & $7.90 \mathrm{E}-06$ & $7.90 \mathrm{E}-06$ & $7.90 \mathrm{E}-06$ \\
\hline
\end{tabular}

Table 5 Material Properties of Elastomeric rubber [7]

\begin{tabular}{|l|c|}
\hline \multicolumn{2}{|c|}{ Elastomeric rubber } \\
\hline conductivity, W/mm K & 0.00014 \\
\hline Specific heat , J/kg K & 1880 \\
\hline density, $\mathrm{kg} / \mathrm{mm}^{\wedge} 3$ & $9.20 \mathrm{E}-07$ \\
\hline
\end{tabular}

Five series of deration series are assumed, and the ablation is studied in all the cases. The graphs and equations showing the series are shown in figure 4 and Table 6.

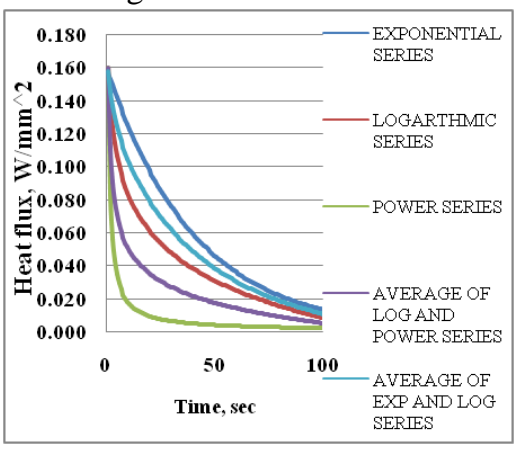

Figure 4: 5-Series of Heat Deration of heat flux

Published By: 
Table 6 Equations of all series of heat flux

\begin{tabular}{|l|c|}
\hline Exponential Series & $\mathrm{y}=0.16 \mathrm{e}^{-0.025 \mathrm{x}}$ \\
\hline Average of Exp and Log Series & $\mathrm{y}=\left((-0.033 \ln (\mathrm{x})+0.16)+\left(0.16 \mathrm{e}^{\wedge}-0.025 \mathrm{x}\right.\right.$ \\
)$) / 2$
\end{tabular}

Transient thermal analysis is performed up to $65 \mathrm{sec}$ and the ablation is studied. It is observed that in all cases the max temperature is below the melting point of composite material. So, ablation happens only in rubber. Therefore ablated, char and virgin thickness of rubber for all cases are shown in the Table 7

\section{RESULTS}

Transient analysis is done for silica phenolic shims using five different series. Among all the series exponential series gives the highest heat flux and power series gives the lowest flux. In all the cases the maximum temperature is below the melting point of silica phenolic. The melting point of silica phenolic is $1800 \mathrm{~K}$ therefore ablation is studied in rubber and results are given in the Table 7 . The temperature distribution of the flex seal system is shown in the Figure. 5

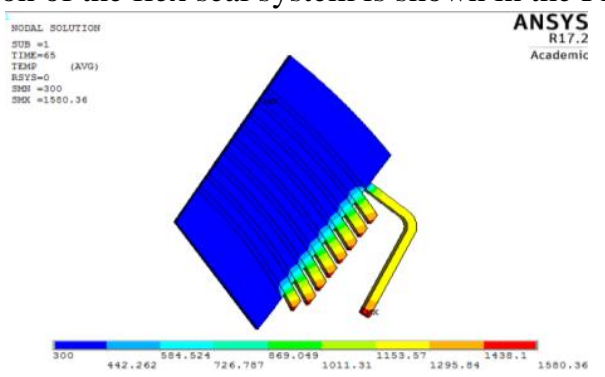

Figure 5: Temperature distribution of Flex Seal with silica phenolic shims

Table 7 Results for the design in all series in-case of Silica Phenolic shims

\begin{tabular}{|l|c|c|c|}
\hline \multicolumn{1}{|c|}{ Name } & $\begin{array}{c}\text { virgin } \\
\text { thickness } \\
(\mathrm{mm})\end{array}$ & $\begin{array}{c}\text { char } \\
\text { thickness } \\
(\mathrm{mm})\end{array}$ & $\begin{array}{c}\text { ablated } \\
\text { thickness } \\
(\mathrm{mm})\end{array}$ \\
\hline exponential series & 77.7975 & 2.14279 & 6.52664 \\
\hline $\begin{array}{l}\text { Average of exponential and } \\
\text { logarithmic series }\end{array}$ & 78.41842 & 2.1422439 & 5.71259 \\
\hline logarithmic series & 78.7975 & 2.14279 & 5.52664 \\
\hline $\begin{array}{l}\text { Average of power and logarithmic } \\
\text { series }\end{array}$ & 82.2549 & 2.8526 & 1.564 \\
\hline power series & 85.5264 & 0.7149 & - \\
\hline
\end{tabular}

Maximum ablated thickness is observed in exponential series and in remaining series the ablated thickness is below $7 \mathrm{~mm}$ which is safe as per industrial norms. As the load value in power series is very less when compared to other series no ablation is seen in power series.

Similar analysis is done by changing the material of shims to carbon phenolic using five different series. Among all the series exponential series gives the highest heat flux and power series gives the lowest flux. In all the cases the maximum temperature is below the melting point of carbon phenolic. The melting point of carbon phenolic is $2300 \mathrm{~K}$ therefore ablation is studied in rubber and results are given in the Table 8 .

Table 8 Results for the design in all series in-case ofcarbonphenolicshims

\begin{tabular}{|l|c|c|c|}
\hline \multicolumn{1}{|c|}{ Name } & $\begin{array}{c}\text { Virgin Thickness } \\
(\mathrm{mm})\end{array}$ & $\begin{array}{c}\text { Char Thickness } \\
(\mathrm{mm})\end{array}$ & $\begin{array}{c}\text { Ablated Thickness } \\
(\mathrm{mm})\end{array}$ \\
\hline Exponential series & 79.12 & 1.9069 & 5.6988 \\
\hline Logarithmic series & 79.175 & 1.9069 & 5.7263 \\
\hline Power series & 86.576 & - & \\
\hline Average of exponential and logarithmic series & 79.1475 & 1.9069 & 5.71259 \\
\hline Average of power and logarithmic series & 82.7186 & 1.9039 & 1.9039 \\
\hline
\end{tabular}

The conductivity of carbon phenolic is slightly higher than the silica phenolic material and the density is less there by the heat penetration will be more and the ablated thicknesses are slightly more than the silica phenolic material. For carbon phenolic material also in all cases the ablation is less than $7 \mathrm{~mm}$ up to $65 \mathrm{sec}$ time of flight.

Similar analysis is done by changing the material of shims to carbon epoxy using five different series. In all the cases the maximum temperature is below the ablating temperature of carbon epoxy. The ablating temperature of carbon epoxy is $2300 \mathrm{~K}$. Therefore ablation is studied in rubber and results are given in the Table 9.

Table 9 Results for the design in all series in-case of Carbon Epoxy shims

\begin{tabular}{|l|c|c|c|}
\hline \multicolumn{1}{|c|}{ Name } & $\begin{array}{c}\text { virgin thickness } \\
(\mathrm{mm})\end{array}$ & char thickness $(\mathrm{mm})$ & $\begin{array}{c}\text { ablated thickness } \\
(\mathrm{mm})\end{array}$ \\
\hline Exponential series & 62.567 & 4.2838 & 19.522 \\
\hline $\begin{array}{l}\text { Average of exponential and logarithmic } \\
\text { series }\end{array}$ & 65.0643 & 4.28446 & 17.13613 \\
\hline Logarithmic series & 63.5653 & 4.28694 & 18.5639 \\
\hline Average of power and logarithmic series & 70.48 & 5.8117 & 9.992 \\
\hline power series & 85.5895 & 0.714 & \\
\hline
\end{tabular}

The conductivity of carbon epoxy is higher than the previous studied materials and the density is higher than the carbon phenolic and lesser than the silica phenolic material. There by the heat penetration will be more and the ablated thicknesses are higher than the carbon phenolic and silica phenolic material. For carbon epoxy material in all cases the ablation is more than $7 \mathrm{~mm}$ up to $65 \mathrm{sec}$ time of flight. Therefore for this type of thermal protection carbon epoxy is not an apt material for shims

\section{WEIGHT REDUCTION}

The weight of new thermal protection system is compared to the weight of classical thermal boot [9] to suggest the best material between carbon phenolic and silica phenolic. As the ablation is exceeded the safe margin in case of carbon epoxy weight comparison is not studied for carbon epoxy material. The results are shown in Table 10.

Table 10 weight comparison

\begin{tabular}{|c|c|c|c|}
\hline \multirow{2}{*}{ Parameter } & $\begin{array}{c}\text { classical thermal boot of } \\
14 \mathrm{~mm} \text { thick }\end{array}$ & $\begin{array}{c}\text { Material of Thermal protection } \\
\text { system }\end{array}$ \\
\cline { 3 - 4 } & $1.20 \mathrm{E}-06$ & $1.44 \mathrm{E}-06$ & $1.65 \mathrm{E}-06$ \\
\hline $\begin{array}{c}\text { density } \\
\mathrm{Kg} / \mathrm{mm} \text {-3 }\end{array}$ & 3.9287 & 3.721 & 4.263 \\
\hline Weight, $\mathrm{Kg}$ & \multicolumn{3}{|c}{} \\
\hline
\end{tabular}

The density of silica phenolic is more than the carbon phenolic material, therefore the weight of silica phenolic system is more than the carbon phenolic system. As the functioning is safe for two materials and carbon phenolic has an added advantage of low weight, 
Carbon phenolic is suggested as the best material for this type of protection system.

\section{OPTIMIZATION OF THE THICKNESS FOR EXTENDED PART}

The thickness of the extended part is $5 \mathrm{~mm}$. This thickness can be made optimum for more weight reduction. From the above results carbon phenolic material is suggested. Therefore the optimization of the thickness of the extended part is done for carbon phenolic material only. The heat flux values and the weight saving results are given in the Table 11.

Table 11 Thickness Optimization

\begin{tabular}{|c|c|c|}
\hline Thickness & $4 \mathrm{~mm}$ & $3 \mathrm{~mm}$ \\
\hline Material & Carbon phenolic & Carbon phenolic \\
\hline Heat flux, W/mm^2 & 0.161145 & 0.16604 \\
\hline weight, $\mathrm{Kg}$ & 3.4033 & 3.0911 \\
\hline \% reduction & 13.373 & 21.320 \\
\hline
\end{tabular}

The thickness of the extended portion is suggested to a value of $3 \mathrm{~mm}$ for more weight reduction. The ablated thickness is also within the safe range.

\section{CONCLUSIONS}

1. In case of material among carbon phenolic, silica phenolic and carbon epoxy. Carbon phenolic is found to be best in ablation and weight reduction point of view. $21.3 \%$ of weight is reduced when compared to classical protection system (Thermal boot).

2. Carbon epoxy is preferred to withstand the structural loads but found ablating more amount of rubber. So, to minimize the ablation redesigning the thermal protection system is required in this case.

\section{REFERENCES}

1. Borie. V, "Ablation of solid-propellant rocket-motor nozzle materials", Spacecraft Propulsion and Power, Paris, May 1993.

2. Clark, R. K., "An Analysis of a Charring Ablator with Thermal Non equilibrium, Chemical Kinetics, and Mass Transfer," NASA-TN-D-7180, L-8670, 19730601, NASA-Langley Research Center, Hampton, VA, June 1, 1973.

3. Naveen. J,"Thermal analysis of flex nozzle of a composite rocket motor casing", PG Thesis MED, VRSEC, Nov- 2013.

4. Ajay, "Finite element analysis of flex nozzle system of solid rocket motor" IJERIA, Vol. 5, Nov-2012.

5. Eswar Kumar "Analysis of flex of rocket nozzle", PG Thesis, MED, VRSEC, Nov-2014.

6. Prakash.D "Study of Non-Linear Static Behavior of Flex Seal of Rocket Nozzle by Varying Number of Shims", PG Thesis, MED, VRSEC, Nov-2015.

7. D. Madhav "thermal analysis of flex seal of a rocket" PG Thesis, MED, VRSEC, Nov-2016.

8. V. Bala Krishna Murthy, G. Samba Siva rao "Prediction of mechanical properties of polymer matrix FRP composites with imperfections using micromechanical finite element analysis" Research Promotion Scheme A, AICTE, 2013.

9. P. Charitha Krishna "Analysis of Thermal Protection System In Flex Seal Of A Rocket Motor" PG Thesis, MED, VRSEC, Oct-20 